\title{
Does a Physical Education lesson affect foot morphology in school-aged children?
}

\author{
Laura Martin-Casado* and Christian Barquín \\ Faculty of Human and Educational Sciences, Universidad Técnica de Ambato, Ambato, Ecuador
}

\begin{abstract}
Background: To analyze the changes in foot morphology in school-age children after a Physical Education lesson. Methods: A total of 10 school-age children (five girls and five boys) with a mean age of $9.3 \pm 0.5$ years that voluntarily participated in this study were included. Measurements of both feet were obtained using a 3D foot digitizer model IFU-S-01 (Japan) in two different moments, before and after a physical education lesson (per-exercise and post-exercise), where different activities involving displacements, jumps, and landings were performed. Results: By comparing foot morphology before and after exercise, significant differences in the arch height were found, which increased after exercise $(p<0.05)$. Forefoot width shows greater changes after exercise but without significant differences $(p=0.07$; effect size [ES] $=0.2)$. Furthermore, a positive correlation between forefoot width and the arch height $(p<0.05)$ and a negative correlation between the distance from the heel to the first metatarsal and the ball width ( $r=-0.7 ; p<0.05)$, were observed. Conclusions: The type of activities undertaken during physical education lesson (displacements, jumps, and landings) increased the pressure on the forefoot, which would lead to larger arch height. Development of children's sport footwear systems should take into account the foot lengths, widths, and heights, for a better fit, preventing future musculoskeletal injuries.
\end{abstract}

Key words: Footwear. Foot. 3D Imaging. Preschool children. Exercise.

\section{¿Afecta una clase de Educación Física a las dimensiones del pie de los niños?}

\section{Resumen}

Introducción: Analizar las variaciones que se producen en las medidas morfológicas del pie de los niños escolares, tras la realización de una clase de Educación Física. Métodos: Participaron voluntariamente 10 escolares (cinco niños y cinco niñas) con una media de edad de $9.3 \pm 0.5$ años. Se llevó a cabo la digitalización de ambos pies de manera consecutiva, a través de un escáner en 3D modelo IFU-S-01, Japón. Se calcularon las dimensiones del pie en dos momentos diferentes, antes y después de una clase de Educación Física (pre y post ejercicio) donde se realizaron diferentes actividades que implicaban desplazamientos, saltos y amortiguaciones. Resultados: Al comparar las medidas del pie antes y después del ejercicio se observaron diferencias significativas en la altura del arco plantar, que fue mayor tras la realización de actividad física ( $p<0.05)$. El ancho del antepié presentó mayores valores tras el ejercicio sin significancia estadística ( $p=0.07$; tamaño del efecto [ES] $=0.2$ ). Además, se observaron correlaciones positivas entre el ancho del antepié y la altura del arco $(r=0.6 ; p<0.05) ; y$ negativas entre la longitud del talón a la cabeza del metatarso l y el ancho del antepié ( $r=-0.7 ; p<0.05)$. Conclusiones: El tipo 
de actividades realizadas durante la clase de Educación Física (desplazamientos, saltos y amortiguaciones) podría causar mayor presión en la zona del antepié, provocando mayor altura del arco plantar. Los sistemas de desarrollo del calzado deportivo infantil deberían tener en cuenta tanto las longitudes del pie, cómo sus anchuras y alturas, para un mejor ajuste del zapato, previniendo lesiones osteomusculares futuras.

Palabras clave: Calzado. Pie. Imagen 3D. Escolares. Ejercicio.

\section{Introduction}

The foot is a complex biological structure, that plays a fundamental role in the chain of motion of the body during locomotion ${ }^{1}$. It is formed by a total of 26 bones, 107 ligaments, 19 intrinsic muscles and 30 joints that oversee the static and dynamic function of the foot ${ }^{1}$. Its correct anatomical and functional development is of vital importance and is influenced by intrinsic factors such as race, age or the body mass ${ }^{2}$; and by extrinsic factors such as footwear or the type of activity ${ }^{3}$.

It is known that the foot is a dynamic structure that adapts in the face of certain situations that implicate mechanical loads such as walking, running or jumping. Most studies associate physical activity with changes in foot morphology. López-Elvira et al. ${ }^{4}$ analyzed the effect that athletic march had on the structures of the foot in 17 young athletes and observed a significant increase in the forefoot after training. McWorther et al. ${ }^{5}$ observed an increase of 2 and $3 \%$ in the foot volume after 10 minutes of walking and 10 minutes of running, respectively. Nevertheless, some authors have not observed any differences in foot volumetrics after physical activity ${ }^{6}$.

Usually, exercise causes dilatation of the plantar footprint, but some areas will be more affected than others according to the sport, load direction and body composition ${ }^{7,8}$. Aydog et al. ${ }^{9}$ analyzed foot changes in relation to the athletic discipline and observed greater indexes of the foot arch in the wrestler's group compared to football players, handball players, and weightlifters. Other authors have reported flattening of the footprint when training with heavy loads ${ }^{10}$ and an increase in the volume of the foot after activities with light loads ${ }^{11}$.

During a class of physical education at school, the foot of the child is subjected to large mechanical loads due to the different exercises and activities that are carried out. The footwear that they use has a fundamental role in the success or failure of these activities, so it must adjust perfectly to the child's foot regarding length, width, height, and perimeter ${ }^{12,13}$. Understanding the changes that exercise induces on the dimensions of the foot during physical education lessons can be of great help for professionals in physical activity and sports. Also, for those studying the interactions between the foot and footwear since these changes involve modifications in the fit of the shoe that will affect its comfort and functionality.

Most studies analyzed changes in the foot induced by physical activity in adults using plantar footprint ${ }^{4,7,14}$, which could be a limitation when putting it into practice by children's footwear companies since, on the one hand, plantar footprint only allows obtaining two-dimension measurements of the foot (excluding height and volumes). On the other hand, a child's foot is not a reduced version of an adult foot. Some authors have used 3D scanning to analyze morphological measures of the foot ${ }^{1,15}$. However, no studies analyzing the effect of physical activity in the feet of children with these methods have been found.

After a bibliographical search, the established goal of this work was to analyze induced variations in the morphological measures of the foot of school-age children after a physical education lesson.

\section{Methods}

Ten school children (five girls and five boys) voluntarily participated in the study, with a mean age, height and body mass of $9.3+0.5$ years, $137.1+8.0 \mathrm{~cm}$ and $33.3+10.3 \mathrm{~kg}$, respectively. All were fifth-year elementary students belonging to a private school in the city of Ambato, Ecuador. Potential neurological or musculoskeletal issues were ruled-out using anamnesis, excluding from the study all subjects with a recent lesion in the lower extremities, skin infections, alterations of the structures of the foot or any other physical or neurological reason that could interfere with exercise.

All subjects were informed of the objectives and characteristics of the study and gave the researcher a letter of informed consent, signed by the father/mother/legal guardian, to be able to participate in the study. This study was approved by the local Bioethics Committee and followed the guidelines for data protection set by the Declaration of Helsinki at all times ${ }^{16}$.

Measurement of the descriptive characteristics was done using a standing scale model 420KLWA (WelchAllyn, U.S.A.) and a stadiometer model 420KLWA 


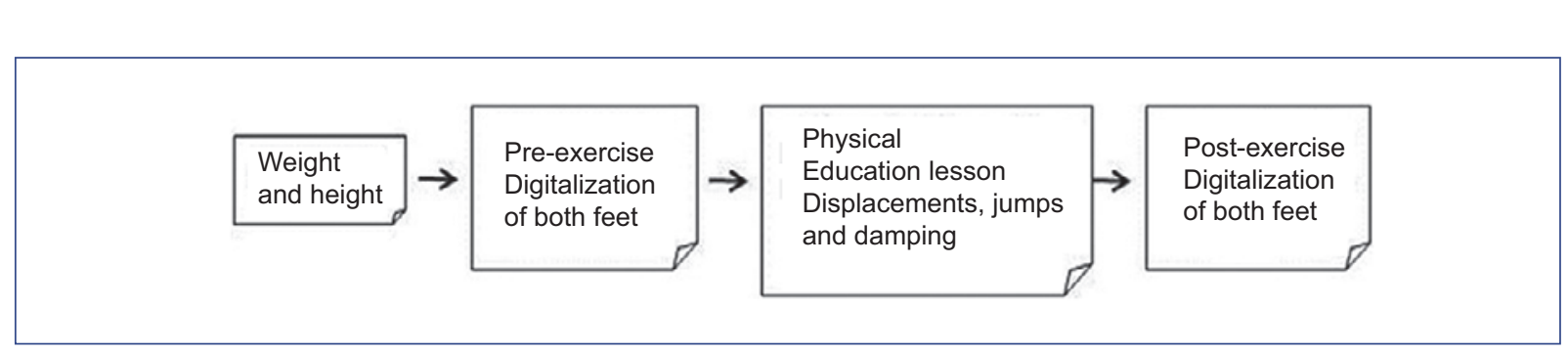

Figure 1. Study design.

(WelchAllyn, U.S.A.). A 3D digital foot scanner IFU-S-01 (INFOOT, Japan) was used to obtain the dimensions of the foot. The system consists of eight cameras and four lasers, as well as software that allows generation of a database of anthropometric foot measures, where individual characteristics of every subject are included.

All subjects took an active part in their regular physical education lesson along with their classmates, for a total duration of 45 minutes, that was directed and supervised by the physical education professor. During this session, activities and games that are usually carried in those lessons were performed; these did not include additional loads to their body weight and included mainly displacements, jumps, and landings. The session was carried out on February 10, 2015, in the schoolyard (asphalt surface) with a maximal ambient temperature of $20^{\circ}$ and a minimum of $11^{\circ}$, consisted in tasks of reaction speed, through relay races in different positions, basketball shooting technique and, finally, a $5 \times 5$ basketball game.

The type of footwear used by the subjects in our study was the standard one required in Ecuador as part of the school uniform in most institutions for Physical Education lessons, classic canvas slippers with laces, thin rubber sole and with a neutral drop.

Before data acquisition, all subjects remained at rest, in the supine position without shoes for 10 minutes $^{5}$, and records of foot measurements were made under basal conditions.

During data acquisition (by three specialists), besides weighing and measuring all study subjects, digital scanning of both feet was performed consecutively, at two different times, before and after physical education lesson (pre- and post-exercise) (Figure 1). To reflect the light of the scanner and to represent the structure of the foot, thirteen marks were placed on the skin of the foot of every subject in different anatomical points ${ }^{17}$, with the subject sat down with both bare feet in a neutral position and with the feet resting on the floor (Figure 2A). Once children had the skin marks correctly placed, 3D scanning of both feet was performed, with

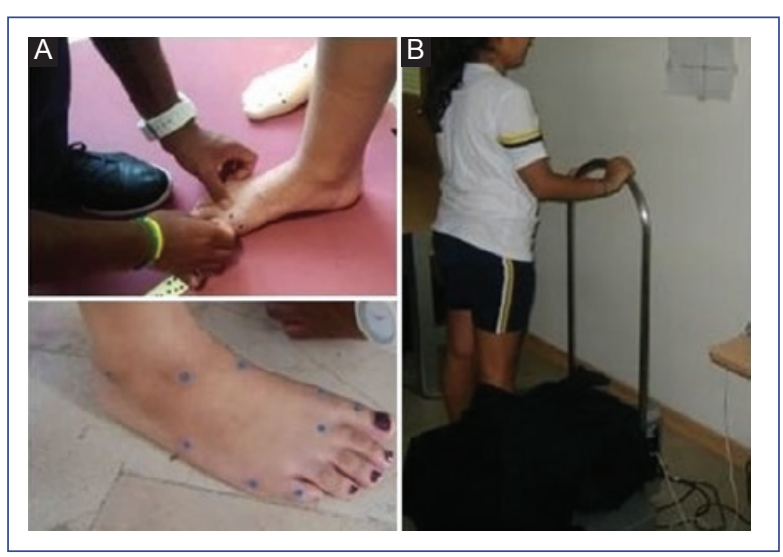

Figure 2. (A) Placement of the 13 marks on the skin in different anatomical points of the foot. (B) Digitization process of both feet with the $3 \mathrm{D}$ scanner.

the subject standing in bipedal support, holding to a handrail with both hands and staring at a target placed $0.5 \mathrm{~m}$ from the scanner (Figure 2B). Duration of the test was less than $10 \mathrm{~s}$.

Measures obtained with the 3D foot scanner are shown in Figure 3 and are described below:

- Foot length: distance between the heel and the most distal point of the phalanges of the foot, which coincided with the distal phalanx of the first and second metatarsus

- Length from the heel to the head of the first metatarsus: distance between the backmost point and the medial region of the head of the first metatarsus.

- Distance from the heel to the head of the fifth metatarsus: distance between the backmost point and the lateral region of the head of the fifth metatarsus.

- Arch height: height from the most prominent point of the scaphoid to the level of the ground.

- Metatarsal head perimeter: maximum circumference covering the head of the first and fifth metatarsus.

- Metatarsal width: distance between the medial region of the head of the first metatarsus and the lateral region of the head of the fifth metatarsus. 


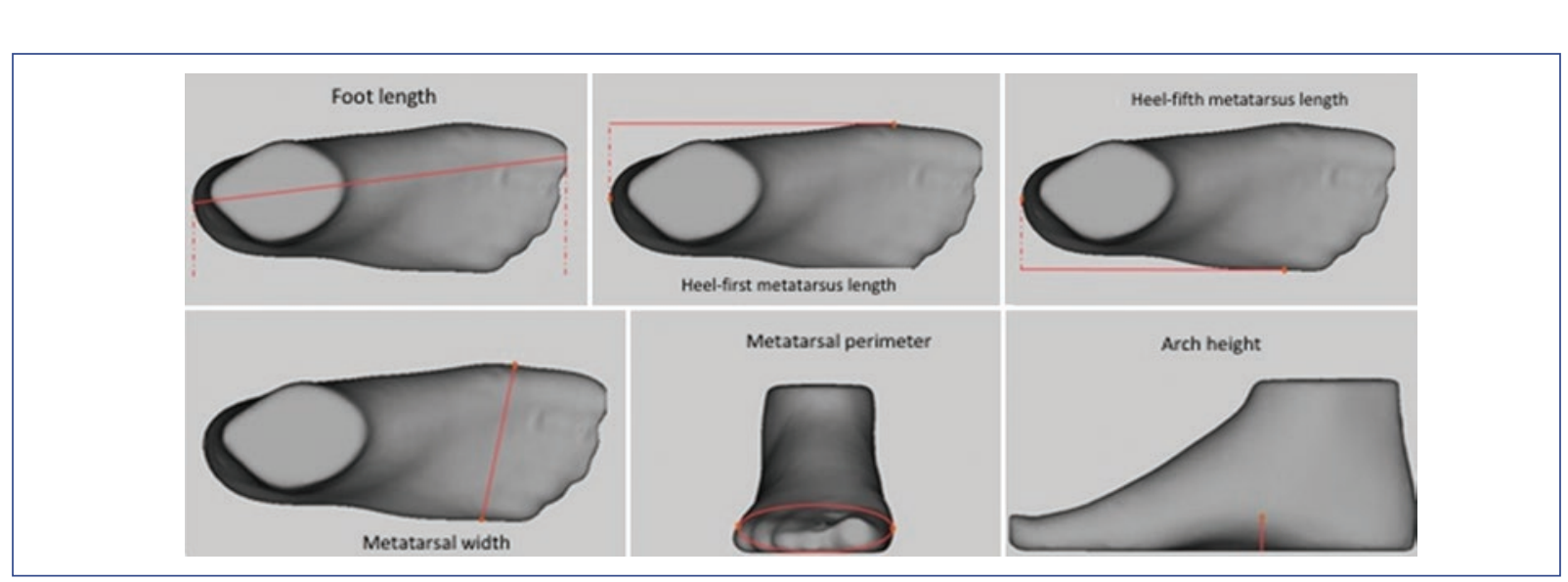

Figure 3. Foot dimensions obtained from the scanner: perimeter of the metatarsal heads, foot length, metatarsal width and arch height.

Data were analyzed with the statistical package SPSS 17.0 for Windows. Non-parametric statistical tests were conducted due to a small size sample.

A Wilcoxon test was used to identify any differences in foot variables pre- and post-exercise. Spearman's tests were done to study any correlation between the variables.

Additionally, statistical power and effect size (ES) of the differences was calculated using Cohen's $d$ index, considering the following thresholds: a small effect for a $d$ value equal to 0.2 , a moderate effect for a $d$ value equal to 0.5 and a large effect for a $d$ value greater than or equal to $0.8^{18}$.

If no significant differences were detected between both feet pre- and post-exercise, analyses were done using measurements of the dominant extremity to represent the foot structure of every child. A minimal level of significance of $<0.05$ was established. Descriptive statistics included mean and standard deviations.

\section{Results}

Values for anthropometric measures of the foot before and after exercise are shown in Table 1.

A positive correlation was observed between forefoot width and arch height $(r=0.6, p<0.05)$ in the post-exercise session; also, a negative correlation was found between the distance from the heel to the head of the first metatarsus and forefoot width $(r=0.7 ; p<0.05)$.

By comparing foot measurements before and after the physical education lesson, significant differences were observed in arch height, which increased after physical activity (pre-exercise $=30.7 \pm 4.3 \mathrm{~mm}$; post-exercise $=35.3 \pm 5.9 \mathrm{~mm}, p<0.05)$. No significant differences were observed in the rest of the analyzed variables.

\section{Discussion}

The results of our study show variations in the morphology of the foot in children of school age after having a physical education lesson. The greatest differences were observed in arch height, which was significantly higher after physical activity (pre-exercise = $30.7 \pm 4.3 \mathrm{~mm}$; post-exercise $=35.3 \pm 5.9 \mathrm{~mm}, p<0.05$ ), which means that subjects in our study showed more cavus feet probably as an adaptation to exercise. These results agree with those of Sirgo and Aguado $^{8}$, who observed a greater percentage of cavus feet by the end of the season in a group of gymnasts as compared to a group of sedentary people. Activities done by subjects in our study during the physical education lesson included mainly displacements, jumping, and landings, that is, light load activities (body weight), very similar to those usually performed in rhythmic gymnastics. However, other authors have reported a greater incidence of the flat foot after an exercise session with heavy loads ${ }^{10}$. The type of athletic activity and the technical gestures used may determine the changes in foot dimensions.

A positive correlation between forefoot width and arch height $(r=0.6 ; p<0.05)$ in the post-exercise session, and both during displacements, as well as in jumping and landings, the forefoot is the first support. This kind of activities, cause a greater pressure over the metatarsal heads overloading the talus and the tarsal bones, which would provoke a greater height of the internal arch to increase the stiffness of feet structures ${ }^{4}$. 
Table 1. Means and standard deviations of the anthropometric measures of the foot.

\begin{tabular}{|l|c|c|}
\hline Variables & Pre-exercise & Post-exercise \\
\hline Foot length $(\mathrm{mm})$ & $210.9 \pm 10.9$ & $209.9 \pm 10.6$ \\
\hline Heel-head of the first metatarsus length $(\mathrm{mm})$ & $155.8 \pm 8.3$ & $154.5 \pm 8.8$ \\
\hline Heel-head of the fifth metatarsus length $(\mathrm{mm})$ & $139.1 \pm 6.8$ & $134.2 \pm 6.1$ \\
\hline Metatarsal width & $81.4 \pm 5.4$ & $82.4 \pm 5.5$ \\
\hline Metatarsal head perimeter $(\mathrm{mm})$ & $196.8 \pm 13.4$ & $198.3 \pm 12.9$ \\
\hline Arch height $(\mathrm{mm})$ & $30.7 \pm 4.3$ & $35.5 \pm 5.9^{*}$ \\
\hline
\end{tabular}

Significance level: ${ }^{*} P<0.05$.

Both forefoot width (pre-exercise $=91.4 \pm 5.4 \mathrm{~mm}$, post-exercise $=82.4 \pm 5.5 \mathrm{~mm}, p=0.13 ;[E S]=0.1)$ and forefoot perimeter (pre-exercise $=196.8 \pm 13.4 \mathrm{~mm}$; post-exercise $=198.3 \pm 12.9 \mathrm{~mm} ; \mathrm{p}=0.95[\mathrm{ES}]=0.1)$ showed greater values after physical activity, without statistical significance and with a small effect size for both variables. These results agree with those of López-Elvira et al. ${ }^{4}$, who observed a significant increase in forefoot width after athletic march training. It is known that exercise induces a dilatation of the footprint in all its parts (forefoot, midfoot and hindfoot), due to an increase in intravascular and extravascular fluid, with some areas more affected than others depending on the type of activity ${ }^{19,20}$. In our study, activities during the physical education lesson involved mainly the forefoot, so it is not surprising that an increase in the width and perimeter of this area was observed.

Lower values in the three measured distances in the post-exercise session were observed, without reaching statistical significance (Table 1), but with a moderate effect size for the distance from the heel to the head of the fifth metatarsus $(E S=0.7)$. Moreover, negative correlations between the distance from the heel to the head of the fifth metatarsus and forefoot width were obtained $(r=-0.7, p<0.05)$. These results are concordant with what was previously mentioned if we considered that an increase in the height of the longitudinal arch causes shortening of the foot and greater pressure over the metatarsal heads ${ }^{4}$.

Most show development systems regarding scale and dimensions of the boot-trees are based on foot lengths to determine shoe size ${ }^{13,21}$. However, in our study, changes in the vertical axis were observed, so height adjustment should also be taken into account at the time of children boot-tree design, since a shoe that compresses the child's foot can impair normal bone development, causing disorders and disease in childhood and later in the adult age ${ }^{22}$.

Shoes used in physical education lessons should be specially designed to do polyvalent exercises. Due to the changes seen in foot dimensions after exercise, it is suggested that special attention is focused on the flexibility of the materials used in shoe fabrication. Therefore, toes may move easily, without compressing the metatarsal area, allowing perception of internal (movement, balance, posture) and external (contact of the sole with the ground) stimuli ${ }^{23}$ during activity. Additionally, heel and longitudinal arch support are important to provide adequate weight distribution ${ }^{24}$, avoiding injuries due to overload or foot instability. Shoes that are appropriate, flexible and well-adjusted to the dimensions of the feet have a definitive influence on functionality and comfort.

On the other hand, it is important that physical education teachers know these aspects when planning their classes. Thus, they can modulate foot demands depending on the proposed exercises. Exercises performed during the physical education lesson relied mainly on the forefoot area. This repetitive pressure exerted over the metatarsal bones can cause stress fractures. Additionally, the fact that a greater height of the internal arch increases the stiffness of the foot structures ${ }^{4}$ causes excessive tension on the soft parts and, consequently, pain and overload in tendons, ligaments, and muscles. Considering these conditions when planning exercises in a Physical Education lesson may prevent future musculoskeletal injuries. According to the characteristics of our students and the type of shoe they used, combination of exercises and activities that require initial contact of the forefoot can be made (changes of direction, tiptoe racing or multi-jumping) with exercises including additional loads (medicine ball) and barefoot exercises over 
different surfaces (park, grass, sand and pads), in conditions of adequate safety and hygiene that lead to foot flattening.

One of the main limitations of our study was the small sample size. We must keep in mind that this is a pilot study, a study before more extensive research that is part of a project that will be developed in the future. By doing statistical power calculations using our number of subjects $(n=10)$, we obtained, for variables such as the perimeter of the metatarsal heads, metatarsal width or length from the heel to the fifth metatarsus, a statistical power of 0.5 and a minimum number of subjects of 14. In the future, it would be interesting to increase sample size and check if these differences could or could not be statistically significant. Greater widths and perimeters of the metatarsals, a decrease or increase of the internal longitudinal arch or changes in foot length, are fundamental when determining shoe fit, especially in children, since at this age the foot is at a continuous process of development ${ }^{1}$. Footwear must respond, regarding functionality and safety, to the variations in foot dimensions of children during physical activity, avoiding possible bone and ligamentous disorders. A wrong show fit could cause pain, fatigue, falls and even gait and balance disorders ${ }^{8,25}$. On the other hand, some authors speculate about the existence of a threshold for the number of support points from which, when a physical activity that involves a greater number or intensity of the support points, does not lead to significant changes in the dimensions of the foot are not produced ${ }^{14}$. The fact that we did not find any significant differences in the lengths or widths of the foot may suggest the existence of a minimum support threshold from which the foot begins to show changes in its dimensions. Nevertheless, in our study, exercise intensity was not accounted, so in future research, it would be interesting to analyze this factor.

To conclude, we can state the following:

1. Significantly greater arch heights were observed after physical activity that included displacements, racing, and landings. Additionally, the perimeter and the width of the forefoot were greater in the post-exercise session, without a statistical significance. The type of activity during the physical education class may cause greater contact with the forefoot area and greater arch height

2. A decrease in foot lengths after exercise was observed, although without statistical significance. Shoe development systems in children should consider both foot lengths, as well as widths and heights, for a better shoe fit.
3. Physical education teachers should know the changes in the foot according to activity so that they can plan exercises in a physical education lesson that modulate foot demands, which may prevent future musculoskeletal injuries.

4. The present study is a pilot. In the future, it would be interesting to increase the sample size and control for the volume and intensity of supports required during activity.

\section{Ethical disclosures}

Protection of human and animal subjects. The authors declare that no experiments were performed on humans or animals for this study.

Confidentiality of data. The authors declare that they have followed the protocols of their work center on the publication of patient data.

Right to privacy and informed consent. The authors declare that no patient data appear in this article.

\section{Funding}

This study is part of a research project that has been jointly financed with research funds from the Universidad Técnica de Ambato and the shoe company Plasticaucho Industrial S.A.

\section{Acknowledgments}

We thank Plasticaucho Industrial S.A. and Carlos Pico Salazar, technical personnel of this company, and his participation in data acquisition. Without their assistance, this study could not have been conducted.

\section{Conflicts of interest}

The authors declare no conflicts of interest.

\section{References}

1. Mauch M, Grau S, Krauss I, Miwald C, Horstmann TA. New approach to children's footwear based on foot type classification. Ergonomics. 2009;52: 999-1008.

2. Saldívar-Cerón H, Ramírez A, Roha M, Pérez-Rodríguez P. Obesidad infantil: factor de riesgo para desarrollar pie plano. Bol Med Hosp Infant Mex. 2015; 72:55-60.

3. Murphy DF, Connolly DAJ, Beynnon BD. Risk factors for the lower extremity injury: a review of the literature. Brit J Sport Med. 2003;37:13-29.

4. López-Elvira JL, Meana M, Vera FJ, García JA. Respuestas, adaptaciones y simetría de la huella plantar producidas por la práctica de la marcha atlética. CCD. 2006;3:21-26.

5. McWhorter JW, Wallmann HW, Landers MR, Altenburger B, LaPorta-Krum L, Alternburger $P$. The effects of walking, running and shoe size on foot volumetrics. Phys Ther in Sport. 2003;4:87-92.

6. Chalk PJ, McPoil T, Cornwall MW. Variations in foot volume before and after exercises. JAPMA. 1995;85:470-2. 
7. Berdejo-del-Fresno D, Lara AJ, Martínez-López EJ, Cachón J, Lara S. Alteraciones de la huella plantar en función de la actividad física realizada. Rev Int Med Cienc Act Fis Dep. 2013;13:19-39.

8. Sirgo G, Aguado X. El niño ante el deporte de competición visto desde el punto de vista biomecánico. A propósito de un estudio transversal basado en la función de apoyo de gimnastas. Perspectivas. 1992;9:31-4

9. Aydog ST, Tetik O, Demirel H.A, Doral MN. Differences in sole arch indices in various sports. BJSM. 2005;39:e5.

10. Jimenéz-Ormeño E, Aguado X, Delgado-Abellán L, Mecerreyes L, Alegre LM. Changes in footprint with resistance exercise. Int J Sports Med. 2011;32:623-8.

11. McWhorter JW, Landers M, Wallmann H, Alenburger P, Berry K, Tompkins $D$, et al. The effects of loaded, unloaded, dynamic and static activities on foot volumetrics. Phys Ther in Sport. 2006;7:81-6.

12. Hawes MR, Sovak D, Miyashita M, Kang SJ, Yoshihuku Y, Tanaka S. Ethnic differences in forefoot shape and the determination of shoe comfort. Ergonomics. 1994;37:187-96.

13. Witana CP, Feng J, Goonetilleke RS. Foot measurements from three-dimensional scans: a comparison and evaluation of different methods. Int $\mathrm{J}$ Ind Ergonom. 2006;36:189-807.

14. Delgado-Abellán L, Aguado $\mathrm{X}$, Jiménez-Ormeño $\mathrm{E}$, Mecerreyes $\mathrm{L}$, Alegre LM. (2012). Efectos del ejercicio continuo e intermitente sobre la huella plantar. AMD. 2012;29:601-8.

15. Chang JH, Wang SH, Kuo CL, Shen HC, Hong YW, Lin LC. Prevalence of flexible flatfoot in Taiwanese school-aged children in relation to obesity, gender, and age. Eur J Pediatr. 2010;169:447-52.
16. World Medical Association International. Declaration of Helsinki: Ethical Principles for Medical Research Involving Human Subjects. JIMA. 2013;107:403-5.

17. INFOOT, compact. Manual 2004. I-Ware Laboratory Co. Ltd.

18. Cohen J. A power primer. Psychol Bull. 1992;112:155-9.

19. Mayrovitz, H.N. Posturally induced leg vasoconstrictive responses: relationship to standing duration, impedance and volume changes. Clin Physio. 1998;18:311.

20. Stick $C$, Stofen $P$, Witzleb E. On physiological edema in man's lower extremity. Eur J Appl Physiol O. 1985;54:442-9.

21. Cheng JC, Leung SS, Leung AK, Guo X, Sher A, Mak AF. Change of foot size with weightbearing. A study of 2829 children 3 to 18 years of age. Clin Orthop Relat R. 1997;123-31.

22. Echarri JJ, Forriol F. The development in footprint morphology in 1851 Congolese children from urban and rural areas, and the relationship between this and wearing shoes. J Pediatr Orthoped. 2003;12: 141-6.

23. Velasco-Climent $P$. Zapatos infantiles: ¿Qué calzado debemos elegir para nuestros hijos? Revista de Enfermería de la Universidad de CastiIla La Mancha. 1997;7.

24. Lampe R, Mitternacht J, Gerdesmeyer L, Gradinger R. Plantar pressure measurement in children and youths during sports activities. Klinische Padiatrie, 2005;217:70-5.

25. Xiong, S, Goonetilleke RS, Witana CP, Lee Au EY. Modelling foot height and foot shape-related dimensions. Ergonomics. 2008;51:1272-89. 